Un análisis fenomenológico interpretativo de los desafíos a los que se enfrentan los profesores universitarios en Pakistán en medio del covid-19

\title{
An interpretative phenomenological analysis of challenges faced by the university teachers in Pakistan amid covid-19
}

Fareyha Said.

University of Malaya.

fareyhasaid@gmail.com

Iffat Ali.

University of Malaya.

iffatali101@gmail.com

Tariq Javed.

Universiti Pendidikan Sultan Idris. tariajaved82@gmail.com

\section{RESUMEN.}

Este estudio tenía como objetivo analizar los desafíos a los que se enfrentan los profesores universitarios durante la transición hacia clases puramente en línea debido al brote de Covid19 en Pakistán. Se utilizó un diseño de investigación cualitativa empleando un enfoque de análisis fenomenológico interpretativo para capturar la experiencia de los profesores universitarios. Se realizaron entrevistas con los participantes seleccionados a través de la técnica de muestreo de bolas de nieve. Y los resultados mostraron que los profesores universitarios en Pakistán tenían que hacer frente a muchos desafíos. Los factores específicos como los problemas de infraestructura, las dificultades de comportamiento de los estudiantes y las dificultades en la evaluación del rendimiento de los estudiantes indican que las aulas físicas son un modo de aprendizaje más eficaz que el modo de aprendizaje en línea. Finalmente, este es uno de los primeros estudios para abordar los desafíos de aprendizaje en línea que enfrentan los profesores universitarios en Pakistán durante el brote de Covid-19.

\section{PALABRAS CLAVE.}

Aprendizaje en línea, Covid-19, Desafíos, IPA

\section{ABSTRACT.}

This study aimed to analyze the challenges faced by the university teachers during the transition towards purely online-based classes due to Covid-19 outbreak in Pakistan. A qualitative research design was used by employing an interpretative phenomenological analysis approach to capture the experience of university teachers. Interviews were conducted with the participants selected through snowball sampling technique. The findings showed that the university teachers in Pakistan had to cope up with many challenges. The specific factors such as infrastructural problems, student's behavioral issues and difficulties in the assessment of student's performance indicate that physical classrooms are a more

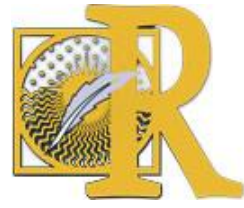


effective mode of learning than the online mode of learning. Finally, this is among the first studies in addressing the online learning challenges faced by university teachers in Pakistan during Covid-19 outbreak.

\section{KEY WORDS.}

Online learning, Covid-19, Challenges, IPA.

\section{Introduction.}

The Covid-19 pandemic has paralyzed almost the whole world. All significant sectors including traveling, economy, health, education, etc. have been adversely impacted, some much more than the others. In Pakistan, the educational system has experienced numerous challenges. The government, educational institutions, teachers, and students were not prepared to cope with this crisis. The government of Pakistan took the initiative to close the educational institutions, urging them to find alternates to physical presence in classrooms in order to continue imparting knowledge to students. Higher Education Commission (HEC), a body that regulates and guides the working of institutions of higher learning in Pakistan, issued elaborate guidelines to higher educational institutions and universities that included utilization of online resources to impart education - the most significant one being to ask the lecturers to take classes online. Universities that had the means and whose students had access to online facilities were quick to respond. Pretty soon a very large percentage of institutions started offering online classes, ushering in a revolutionary change in the character of our higher education environment.

In Pakistan, the Covid-19 and online teaching both are novel. Just as the medical system was insufficient to handle health crisis, the educational system was not well prepared to take technologies on board to meet online teaching requirements. Although it was unusual for students, however it posed more challenges for teachers to explore new areas of technologies to replace century old traditional system of teaching in Pakistan.

The present article is aimed at exploring and documenting the experience of online teaching in Pakistan amid COVID-19, where formal education (face-to-face) was replaced by computermediated communication. Although technologies including internet have been incorporated in educational system of Pakistan since the turn of century; however, its usage was restricted primarily to IT related subjects. Almost the entire formal education system employed face to face teaching at universities and educational institutions till the advent of Covid19. Perhaps out of lack of alternative, with the arrival of COVID-19, supplementary technologies became sole educational source, and online classes became mandatory. Although Pakistan's internet penetration ratio is second highest in South East Asia, and the concept of online or e-learning is not novel in Pakistan, yet the direct and sudden shift to online education proved to be a bitter-sweet experience to both the teachers and students in Pakistan. The presented IPA study intends to discuss and understand the university teachers' experience in this sudden shift, their problems with technologies and student's behavior, time management for personal and professional life while staying at home, involving students in online classes and enduring psychological challenges in COVID-19 trauma, and fulfilling their professional commitments. The study emphasizes on teacher's perception and challenges in COVID-19 situation.

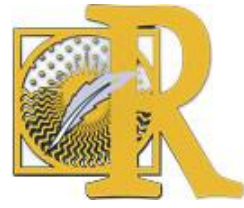




\section{Online Teaching in Pakistan.}

Online teaching is referred to the usage of web-based software to dispense and manage the course on the internet. Technological advancement permits delivery of knowledge in a dialogic manner. The features of dialogic communication on the online teaching platforms include chat rooms, discussions, surveys, polls, and content sharing. These features can help in convenient learning. Google Meet, Microsoft Teams, Edmodo, Zoom, and Moodle are some of the commonly used learning tools for video conferencing in Pakistan.

Considering the urgency and importance of online teaching in Pakistan, a study was conducted recently which supported the effectiveness of online education (Mukhtar, Javed, Arooj, \& Sethi, 2020). However, it concluded with citing numerous challenges, including insufficient institutional capabilities, lack of appropriate or adequate training for the faculty and non-serious attitude of students. Other studies explored and examined the inclination of students towards online teaching system and found lack of technological familiarity and less motivation among the students (Hashmi \& Shuja, 2020). In a situation, where students lack both a technological knowledge and motivation, the responsibilities of teachers increase significantly to keep interest of students and perform their assigned task. Many researchers have recommended strategic planning to provide technological training alongside improving teacher's professional and personal capacities through development programs (Abdullah \& Mirza, 2020).

\section{Significance of the Study.}

Since Covid-19, the educational research mainly focused on the problems and impacts of online teaching for students (Akram, Anjum, \& Batool, 2020). In contrast, this study is an interpretative effort to assess the lived experience of university teachers. Although it is limited to only seven interviews and Pakistan but providing an in-depth understanding of online teaching experience in a country, which has observed exponential technological growth but still lacks cognitive understanding of technologies. The study is significant for utilizing the IPA methodology and analysis which reveal the real-life experience of faculty during Covid-19, including their perception, experience, personal and professional life, and challenges to remain a successful teacher in virtual communication. The review of the literature presented that up till now no such study is conducted specifically in Pakistan and in other countries during covid-19, which adopted IPA analysis.

\section{Methodology.}

\subsection{Method.}

The qualitative method for the current research was employed and in-depth interviews with selected participants were conducted. In qualitative research, the data is collected through interviews, focus groups, observation, and document analysis. However, according to objective of presented research and research question, Interpretative phenomenological analysis (IPA), as qualitative research design is used for the present study (Creswell, 2016; Dean, Smith, \& Payne, 2006; Smith). IPA methodology focuses on individual's personal account of an event to produce a subjective view; however, researchers can subsequently

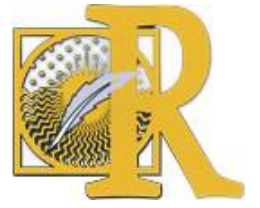


draw objective inferences and statements from the event (Smith et al., 1999). The IPA studies aim to gain in-depth understanding of participant's view of the phenomenon from an insider's perspective of the phenomenon in question. IPA provides an access to participant's personal experience. However, it is mandatory to obtain required sensible data by engaging participants (Dean et al., 2006; Smith et al., 1999).

\subsection{Participants.}

The study was conducted at Islamabad (Federal Capital of Pakistan) in July 2020. The participants include university male and female faculty members, teaching at graduate and post-graduate level. According to Higher Education Commission (HEC), Pakistan, 21 universities have campuses in Federal Capital, including 15 from public and 6 from private sector. In 21 universities, including public and private, 4462 faculty members are engaged in higher education.

\subsection{Sampling.}

For the research, snowball sampling technique is employed. However, sample inclusion and exclusion criteria were determined rigorously. Faculty members, who are teaching undergraduate and postgraduate level, simultaneously, are included in potential participant list.

Snowball sampling technique (also referred to as chain method) was deemed helpful and time effective in finding people who would otherwise be very difficult to access. Therefore, researchers of the study selected first few participants conveniently within their contacts and asked them to involve their fellows, who fulfil the interview criterion. The snowball method not only takes less time but also provides the researcher with the opportunity to communicate better with the samples, as they are acquaintances of the first sample, and the first sample is linked to the researcher. This type of networking is particularly useful for finding people and gaining optimal information. The selected respondents of the study are experienced teachers with at least five years' practical experience, taking online classes and having thorough understanding of their responsibilities during COVID-19 situation and are committed to their jobs and academic career.

\subsection{Data Collection.}

The semi-structured interviews are taken in IPA to generate dialog and engage participants, to enable the researcher to access the participants' "lived experience". The dialogic conversation between researcher and participants results in better understanding and reveal rich, reliable information regarding the studies phenomena. Memo writing, during interview is essential part of IPA research, as these analytic memos (Gibbs, 2014) help immensely in tabulating the results. In memo, the researchers write the summary of the patterns according to researcher's analysis that facilitate in final report (Krueger, 2014).

Following the advice of Smith and Osborn (2008), the researcher used semi-structured interviews to facilitate an informal, flexible conversation. The researcher asked questions in an open-ended and non-leading style in order to get as close to the participants' views as possible and followed each interview with detailed notes about the experience. Notes included

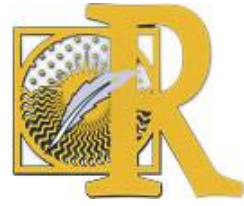


initial thoughts, feelings, and impressions. Participants were interviewed at their residence and each interview lasted from 30 to 45 minutes. The audio was recorded and transcribed. The written responses of the investigator along with the interview transcripts became the raw data that the researchers analyzed.

\section{Data Analysis.}

IPA analysis involves multiple stages of analysis. Accordingly, IPA has been used to 'theme' and interpret our interview transcripts by adopting Smith and Osborn's (2008) approach which respects the structure of data. The researcher engaged in an iterative process of reading and listening to each transcript, during which notes, and memos were made in the left-hand margins of the transcript to record anything interesting or significant. The notes and memos constituted a summary of content as well as comments or connections, similarities, differences, contradictions, and preliminary interpretations. Transcripts were then re-read, and the right-hand margins were used to document emerging themes. This involved moving to a higher interpretative level of abstraction, general enough to allow theoretical connections within and across cases while remaining grounded in what the participant said (Creswell, 2016). This process was repeated for all interviews, each interview in its own light, respectively, as separate, and individual from the other interviews.

Following the guidelines for IPA, initially each transcript of interview was reviewed exploratively and researchers noted their comments while reading the interviews. Consequently, the line by line reading helped the researchers to identify important codes. Later, the researchers read the interviews for a second time to get a deeper understanding of the participants, which were specific to the objective of this study. During the reading, the researchers combined their comments, notes, and identified the emergent themes.

Although commonalities in themes were noticed, all issues were identified in each transcript as they emerged, thus the researcher paid attention to ways in which accounts from participants were similar or different (Smith \& Osborn, 2008). When all interviews had been analyzed and superordinate themes and theme clusters identified, a master list of themes and sub-themes was created. It provided a coherent framework for understanding the value, the participants assigned to online teaching experience. The master list of themes and subthemes was translated into a narrative account, as the purpose of an IPA is to try to understand the content and complexity of the participant's meanings rather than measuring their frequency. It involves the investigator engaging in an interpretative relationship with the transcript. Care was taken to ensure that a distinction was made between what the participants said and the researcher's interpretation.

\section{Findings and Discussion.}

The presented IPA study focused to understand the essence of teacher's online experience during COVID-19 and finding out their real-life experience of trying to be "successful" in achieving academic objectives/ goals. The collected data through interview has been interpreted for the meaning of the lived experience and yielded meaningful themes and findings.

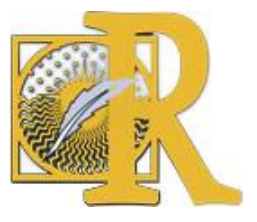




\subsection{Participants Profile.}

Overall, the participants were well-experienced faculty members from higher education institutions and universities. Most of the participants for this study were males with a Ph.D. degree. In Pakistan, MS/ M.Phil. degree holders can also teach at the university level. Hence, three participants were MS/ M.Phil. degree holder. The participants belonged to both public and private sectors and mostly used Zoom and Microsoft teams for online lecturing.

Table 1: Participant's profile

\begin{tabular}{llc}
\hline & & Frequency \\
\hline Gender & Male & 5 \\
& Female & 2 \\
\hline Education & MS/M.Phil. & 3 \\
& Ph.D. & 4 \\
\hline University sector & Public & 4 \\
& Private & 3 \\
\hline Software & Google meet & 1 \\
& Microsoft Teams & 2 \\
& Zoom & 2 \\
& Others & 2 \\
\hline
\end{tabular}

\subsection{IPA Thematic Analysis.}

The IPA analysis helped the researchers to analyze the data in an organized manner, making it possible to identify the relevant themes for discussion. After going through each interview transcript and making initial comments and notes to familiarize ourselves with the online teaching experience of faculty in Pakistan during Covid-19, we analyzed the data. The analysis revealed that participants have some serious concerns about online teaching in Pakistan during Covid-19. With limited facilities, they are fulfilling their professional responsibilities and making efforts to continue their assigned jobs. The analysis of the interviews is based on their real-life experience from which below themes, along with subthemes are drawn (Table 2).

Table 2: Emerging Themes and Sub-Themes

\begin{tabular}{|c|c|}
\hline Themes & Sub-Themes \\
\hline \multirow{3}{*}{$\begin{array}{l}\text { 1. Perception of teachers about Online } \\
\text { teaching }\end{array}$} & Challenging task \\
\hline & Additional responsibilities \\
\hline & Preference for face-to-face class \\
\hline \multirow[t]{3}{*}{ 2. Online teaching experience } & Insufficient awareness and training \\
\hline & Student's behavioral issues \\
\hline & Lack of technological infrastructure \\
\hline \multirow{3}{*}{$\begin{array}{l}\text { 3. Challenges during Covid-19 online } \\
\text { teaching }\end{array}$} & Psychological impacts \\
\hline & Imbalance between personal and professional life \\
\hline & $\begin{array}{l}\text { Difficulties in the assessment of student's } \\
\text { performance }\end{array}$ \\
\hline
\end{tabular}




\subsubsection{Theme One: Perception of the Teachers about Online Teaching.}

The participants were asked to share their perception of teaching online. Since technology has revolutionized pedagogical practices, therefore, online teaching training has become an essential aspect of teacher training programs (Morris \& Finnegan, 2009; Oomen-Early \& Murphy, 2009). However, despite wide ranges of teacher's training, even experienced teachers show reluctances in online teaching (McQuiggan, 2007).

Likewise, technologies have been incorporated in the educational system of Pakistan, but the perception of participants revealed that they were quite shocked to know about the transfer to online teaching mode at first. A participant, while sharing his first impression about teaching, said, "It would not be practical and feasible". Another participant called it a "challenging task". A similar response was given by another participant who belonged to a public sector university, "A challenge at first, to be honest".

The expression of participants and their perception of online teaching suggests that although technological penetration in Pakistan is at par with other developing countries, it lacks the planning of utilizing available technologies in teaching practices. The outbreak of COVID-19, which resulted in the closure of educational institutions worldwide (Burgess \& Sievertsen, 2020) exposed the lack of online teacher's training programs. As the participants of the study teach at a higher level, therefore, their astonishing perception of online teaching explains the loopholes in the educational system of Pakistan. Despite claims and investment of massive budget, universities could not involve teachers in online pedagogical practices.

Consequently, with a shocking and unpleasant impression by the participants, they considered it an additional workload or responsibility apart from their traditional roles. Typically, in Pakistan, there is no compulsion for faculty members to deliver lecture through PowerPoint slides. They rely on the flow of discussion and experience. However, to deliver lectures online, they had to put in additional efforts to record the lecture before class time. Also, they had to make material that can be shared on the screen during the online lecture. A participant stated that it is difficult in finance and mathematics-related disciplines to deliver the online lecture. Unfamiliarity with the process has a scaring effect that translates to the perception of difficulty. The participant remarked that making the slides for lectures, recording video lectures, designing quantitative or mathematical questions for use in an online class, seemed daunting. While another lecturer stated that, "Preparing video lectures and online sessions separately is extra workload for me". As the Pakistani students, as well as teachers, are not well acquainted with the new lecture environment, especially the teachers faced difficulty in steering and leading the discussion during the lecture. A participant stated that "class discussion and interaction with student is like an extra workload". Hence, the overall learning process of online teaching has added additional responsibilities for faculty members in Islamabad, Pakistan.

However, on a positive note it can be said that while the online teaching experiences reflected additional workload on the faculty members in Pakistan, the participants of this study were self-motivated to learn and adapt according to the new requirements. This demonstrates their dedication to their profession. A participant openly shared his experience in these words, "I learnt it myself by exploring the things in detail and getting help from google". At the same

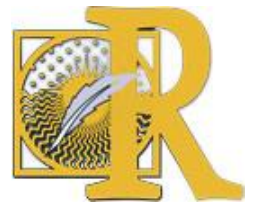


time, another participant stated that he learned the techniques from his colleagues. He added, "from discussion with colleagues".

It is evident that due to COVID-19, the shift towards online teaching was daunting by most faculty members in Pakistan who felt that were being encumbered with additional responsibilities. Understandably, faculty teachers preferred the traditional mode of classes, otherwise known as a physical class in the university. It would be a fallacy to assume that the sole cause of lecturers' dissatisfaction with online classes was lack of prior exposure to online teaching techniques. Several reasons were narrated by the participants for preference for the physical classes. A participant acknowledged that online lectures are delivering some knowledge to the students, but he preferred face to face classes over online classes in these words, "Physical for sure. But it may vary from subject to subject but for finance and accounting face to face is a way better. But the exposure side is highly lacking in online classes which is possible in face to face classes". Another participant, when asked to name his preferred mode, said "physical classroom teaching". All the participants in this study agreed on the conclusion that physical classrooms are the more authentic source of imparting knowledge as compared to the online classrooms.

The perception of the teachers about online teaching is challenging (Li \& Irby, 2008) as they are habitual of face-to-face teaching. Despite, the switch from traditional teacher to online tutor (Syverson \& Slatin, 2010), additional tasks without the support staff, and lack of online teaching training (Behera, 2013), the participants are performing their assigned responsibilities.

\subsubsection{Theme Two: Online Experience.}

At the higher education level, universities and institutions adopt a flexible method of teaching; however, the experience of the teachers in Pakistan explained that still traditional teaching strategies are followed. The interviews with the participants highlighted the real-life experience of teachers, and they referred to numerous obstacles, which they faced while teaching online. According to the participants of this research, as per the challenges posed by COVID-19, a few institutions provided quick training to their faculty members after the unexpected transition towards the online class. However, not all the institutions in the sample of this study were able to guide, train or provide a proper instruction manual to the faculty members. One of the participants surprisingly remarks that "Yes in case of visiting, No in case of full time".

Further, a participant highlighted lack of resources for a full-fledged training for software and related tools. Also, another participant acknowledged that some training is better than no trainings at all, adding that training provided to him was "Sufficient, but due to short time it was not very extensive". It can be inferred that this sort of migration from traditional physical classes to online classes in such a short period was a considerable challenge for academia in Islamabad, Pakistan, considering the meagre amount of resources at the disposal of educational institutions.

The insufficient training indicates the lack of resources and absence of policies to meet the unexpected crisis in the educational sector, in particular, among universities of Pakistan. Although, researchers recommended to transform the educational system and practices in the presence of technologies (Salifu \& Todd, 2020).

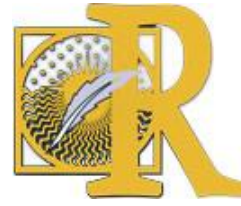


Another online teaching experience is based on the student's behavioral issues. Although like teachers, it was a new experience for students as well, however, teachers had to cope up students' behavioral issues, such as absences, non-serious attitude, and lack of involvement in the lecture.

A mixed response from participants regarding the student's involvement was observed. One of the participants answered that the students were sceptical. He stated, "Yes, they were sceptical initially but improved with time". Another participant, who belonged to the private sector said he felt $70 \%$ of the students showed serious intention for learning. However, another participant from a private sector university said, "Not fully interactive: 50:50 Ratio". Apart from the lack of interaction during online classes, the students also showed minimal interest in the online class. The teachers had to incentivize them with attendance and good grades to ensure and encourage their participation. A participant answered as, "we had to resort to devising class activities, engaging them in active class participation and making sure that their attendance will count in final grade evaluation". On the other hand, some students were serious and ambitious to learn. They felt frustrated by the online mode of classes. A participant remarked, "Those students who have no interest in studies obviously preferred it, but there were some students, in fact the brighter students who felt frustrated by this methodology".

Earlier online teaching research stressed on the transformative and engaged online learning (Mezirow, 2000), not only to involve students but also to foster a positive relationship. Provision of timely feedback and setting realistic expectations can reduce stress among teacher and student in an online learning environment (Hogan \& McKnight, 2007; Hislop \& Ellis, 2004).

In continuity, the participants also shared problems and significant deficiency of infrastructure, which causes hindrances in the online classes. The infrastructural defects disrupt the flow of conversation for the teachers and break in the interests of the students. Regardless, the teachers opted for every possible solution to facilitate the students. A participant even sent CD's to the students who had no internet access, "The lectures were recorded beforehand as well as the online sessions were recorded; so later these were shared through WhatsApp groups/emails/Google Drive/YouTube. CDs/DVDs were sent to some students who belonged to far-flung areas and no access to internet". Many teachers had to compensate students who belonged to far-flung underdeveloped areas of Pakistan, "Most of them used $3 \mathrm{~g}$ or $4 \mathrm{~g}$ mobile packages at the time of class rather than using landline net. In some serious cases, margin was given in attendance and their evaluation as well." Not all the teachers went to extra lengths to facilitate the students. Some of them just gave in, as a participant stated that, "it is an uncontrollable factor". The problems such as power outages have also contributed to the difficulties of online teaching. There is no standard time of power outages throughout Pakistan. When the students and teachers are at different geographical locations, it indeed becomes an uncontrollable factor. A participant confirmed the power outage issue for both teachers and students in these words, "Yes both types (power outage and internet dis-connection). Both teachers and students faced similar problems".

When it comes to technology, Orlando and Attard (2015) stated that "teaching with technology is not a one size fits all approach as it depends on the types of technology in use at the time

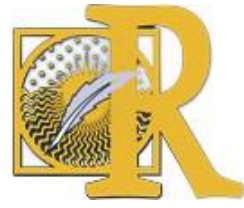


and also the curriculum content being taught" (p. 119). Therefore, universities in Pakistan need to assess and devise policies accordingly.

\subsubsection{Theme Three: Challenges during Covid-19.}

The shift to online learning during Covid-19 has pushed all walks of life to adopt new changes. In this scenario, the teachers also experience psychological issues while shifting their responsibilities in the digital world. The participants shared psychological issues, including work pressure, imbalance in personal and professional life, and difficulties in the assessment of student's performance. Also, learning online teaching strategies caused psychological issues and stress. When the participants were asked about what came to their mind when they first heard about online lectures, they responded as, "A challenge at first, to be honest". While in a similar tone, the pressure was expressed by a participant, "How to manage/handle the class?". Another participant elucidated his expression as a simple, "FATIGUE" in capital letters.

Likewise, staying home and mixing work and domestic environment enlarged the stress among the teachers. As the participants narrated that they felt uneasy and the increased psychological pressure and absence of a separate workspace caused an imbalance in the personal and professional life. Because there is mostly joint family system in Pakistan, this eliminates the luxury of having a separate space in large families. One participant who belongs to an extensive family system commented on the question of whether their personal life was affected due to online class system as, "Not to a great extent, but yes to some extent". Another participant answered in an affirmative tone that yes, he faced an imbalance in his professional and personal life. Nevertheless, most participants in this study responded that their personals lives were not unduly affected. Upon further investigation, it showed that these were those participants who were living alone or in a small family system. Work from Home phenomenon is still far from gaining general acceptance in Pakistan - it is disliked (if not disapproved) as much in academia as in industrial and commercial sectors.

Further, the participants described that student's performance assessment was a significant challenge. Increased Plagiarism is observed in their assignments, and most of the time, cutand-paste segments were submitted. A participant of this study stated that "In online system, it very difficult to put the barriers on students. In some cases, or subjects where the assessments or tests can be given individually, we can control this thing. But in most cases, the copy paste element cannot be controlled. For this purpose, we need to provide the trainings to students, counsel them and make them ready to take challenges during online classes. It is quite difficult to control or stop a student from copying the assignment in physical classroom; in case of online system the difficulty is much greater and more difficult to control". For the resolution of this issue, one of the participants suggested the use of sophisticated (plagiarism testing) software, to make assessment easy for the teachers. He commented, "specialized software coupled with teachers and students training could make this effective". Similarly, the importance of training was emphasized by another participant as, "Not to a great deal. There are shortcomings in online assessment. Training is needed in this area to improve".

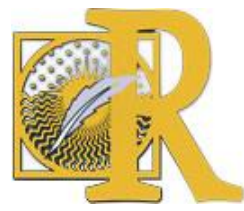


The grading of student's online examination also proved to be challenging for most university teachers - they had several suggestions for more reliable grading of the students. "Students seem to perform better on online assignments, on average, but the reasons are different from the effectiveness of online teaching per se. The prime cause of better performance appears to be the fact that as first-time experience institutes were lenient, flexible, and more cooperative. Similarly, the assessment system was not very effective due to the lack of training in this particular area of online teaching." It can be deduced that the notion of online classes being a temporary substitute for the physical classes leads to lenient performance evaluation of the students. However, if the institutions may want to opt for online classes as a permanent mode of teaching, then training must be provided to both teachers and students".

To sum up, the challenged of online teaching amid COVID-19 in Pakistan, it is observed that teachers faced multiple problems and psychological pressures.

\section{Conclusion.}

The current IPA study exhibited the challenges of teachers in an online environment in Pakistan. The study concludes that the Covid-19 situation has had diverse and adverse impacts on all fields of life in the country education has been suffering in many ways. The online teaching seems to be quite challenging for teachers and students in almost every country in the world. Even though most of the universities of the developed countries are technologically advanced, yet online teaching may have drawbacks for these countries as well. This is making distance learning complicated. There are deferrals in systematized testing, evaluation, and assessment systems of the educational institutions throughout the world.

Generally, in Pakistan, the situation becomes more complicated due to huge issues, such as lack of adequate technological infrastructure, institutional incapability, lack of professional training for faculty, students' behavior, embedded cultural attitudes and family set up. The lived experience of faculty has helped us understand the teacher's efforts to adapt themselves according to new growing challenges in academia. Despite the lack of professional training by institutions, the faculty did their best to learn and perform their professional responsibilities. The online teaching increased their workload as well as responsibilities, which caused mental distress to them. The first mental and psychological condition was to remain at home, and in such a situation, while staying at home, they continued to perform their assigned tasks.

\section{Limitation and Recommendations.}

While we believe that the sample size relied upon by us was adequate for this research, it is acknowledged that a larger sample could produce more refined and reliable conclusions. Covid-19 itself constrained us from reaching a larger number of lecturers as many of them were working from homes outside Islamabad. Also, due to increased workloads and added responsibilities bestowed on lecturers by Covid-19, even telephonic interviews were not possible. It is hoped that a subsequent study can build upon our questionnaire and gather data from a larger sample from Islamabad, or more cities of Pakistan.

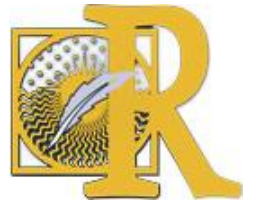

Fecha de recepción: 28-08-2020 Fecha de aceptación: 09-10-2020

Said, F., Ali, I. \& Javed, T. (2021). Un análisis fenomológico interpretativo de los desafíos a los que se

enfrentan los profesores universitarios en Pakistán en medio del covid-19

International Journal of Educational Research and Innovation (IJERI), 15, 260-272

ISSN: 2386-4303 DOI https://doi.org/10.46661/ijeri.5256 


\section{References}

- Abdullah, N. A., \& Mirza, M. S. (2020). Evaluating Pre-Service Teaching Practice for Online and Distance Education Students in Pakistan: Evaluation of Teaching Practice. The International Review of Research in Open and Distributed Learning, 21(2), 81-97.

- Akram, M., Anjum, F., \& Batool, Z. (2020). Covid-19: A Reason behind Digital Education in Pakistan. Mediterranean Journal of Social Sciences, 11(4), 19. https://doi.org/10.36941/mjss-2020-0037

- Anwar, M., Khan, A., \& Sultan, K., (2020). The Barriers and Challenges Faced by Students in Online Education during Covid-19 Pandemic in Pakistan. GOMAL University Journal of Research, 36(1), 52-62.

- Behera, S. K. (2013). E- and m-learning: A comparative study. International Journal on New Trends in Education and Their Implications, 4(3). 65-78.

- Burgess, S., \& Sievertsen, H. H. (2020). Schools, skills, and learning: The impact of COVID-19 on education. VoxEu. org, 1.

- Choi, M., Cristol, D., \& Gimbert, B. (2018). Teachers as digital citizens: The influence of individual backgrounds, internet use and psychological characteristics on teachers' levels of digital citizenship. Computers \& Education, 121, 143-161.

- Creswell, J. W., \& Poth, C. N. (2016). Qualitative inquiry and research design: Choosing among five approaches. Sage publications.

- Dean, S., Payne, S., \& Smith, J. (2006). Low back pain: exploring the meaning of exercise management through interpretative phenomenological analysis.

- Eatough, V. and Smith, J.A., (2008). Interpretative phenomenological analysis. The Sage handbook of qualitative research in psychology, 179, 194.

- Gibbs, G.R., 2014. Using software in qualitative analysis. The SAGE handbook of qualitative data analysis, 277-294.

- Gillett-Swan, J. (2017). The challenges of online learning: Supporting and engaging the isolated learner. Journal of Learning Design, 10(1), 20-30.

- Hashmi, M. U., \& Shuja, S. (2020). The Barriers and Challenges Faced by students in Online Education during Covid-19 Pandemic in Pakistan. Gomal University Journal of Research, 36(1), 30-39. Retrieved from http://www.gujr.com.pk/index.php/GUJR/article/view/1115

- Hislop, G. W., \& Ellis, H. J. (2004). A study of faculty effort in online teaching. The Internet and higher education, 7(1), 15-31.

- Hogan, R. L., \& McKnight, M. A. (2007). Exploring burnout among university online instructors: An initial investigation. The Internet and Higher Education, 10(2), 117-124.

- Krueger, R.A., (2014). Focus groups: A practical guide for applied research. Sage publications.

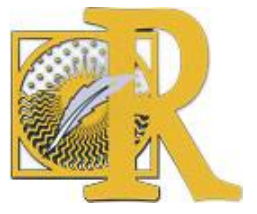


- Li, C., and Irby, B. (2008). An overview of online education: Attractiveness, benefits, challenges, concerns, and recommendations. College Student Journal, 42, 449-458.

- McQuiggan, C. A. (2007). The role of faculty development in online teaching's potential to question teaching beliefs and assumptions. Online Journal of Distance Learning Administration, 10(3), 1-13.

- Mezirow, J. (2000). Learning as Transformation: Critical Perspectives on a Theory in Progress. The Jossey-Bass Higher and Adult Education Series. Jossey-Bass Publishers, 350 Sansome Way, San Francisco, CA 94104.

- Morris, L. V., \& Finnegan, C. L. (2009). University System of Georgia's eCore: Virtual general education. New Directions for Higher Education, 146, $25-34$.

- Mukhtar, K., Javed, K., Arooj, M., \& Sethi, A. (2020). Advantages, Limitations and Recommendations for online learning during COVID-19 pandemic era. Pakistan Journal of Medical Sciences, 36(COVID19-S4), 27-31. https://doi.org/10.12669/pims.36.covid19$\underline{\text { s4.2785 }}$

- Oomen-Early, J., \& Murphy, L. (2009). Self-actualization and e-learning: A qualitative investigation of university faculty's perceived barriers to effective online instruction. International Journal on E-Learning, 8(2), 223-240.

- Orlando, J., \& Attard, C. (2015). Digital natives come of age: The reality of today's early career teachers using mobile devices to teach mathematics. Mathematics Education Research Journal, 28, 107-121. doi:10.1007/s13394-015-0159-6

- Salifu, M., and Todd, R. (2020). Ghana's Teacher Education System and Responding to COVID-19. Retrieved from: https://www.ttel.org/news-view/ghanas-teacher-educationsystem-and-respondingto-covid-19

- Smith, J. A., \& Osborn, M. (2008). Interpretative phenomenological analysis, in J.A. Smith (Ed). Qualitative Psychology: A practical guide to research Methods (2nd edn). Sage: London.

- Smith, J. A., Jarman, M., \& Osborn, M. (1999). Doing interpretative phenomenological analysis. Qualitative health psychology: Theories and methods, 218-240.

- Syverson, M. A., \& Slatin, J. (2010). Evaluating learning in virtual environment. Retrieved from: http://www.learningrecord.org/caeti.htm 